\title{
Reflexiones sobre género y protección jurisdiccional de los derechos políticos de las mujeres
}

\section{Santiago Nieto Castillo*}

\section{Paloma Orona García**}

\section{Sumario:}

I. Introducción

II. Los derechos de las mujeres

III. Juzgar con perspectiva de género: la práctica de hacer visibles las discriminaciones

al momento de impartir justicia

IV. Conclusiones

* Doctor en Derecho por la UNAM. Profesor de las divisiones de estudios de posgrado de la Universidad Nacional Autónoma de México y la Universidad Panamericana. Actualmente es magistrado presidente de la Sala Regional Toluca del Tribunal Electoral del Poder Judicial de la Federación.

** Licenciada en Ciencias de Comunicación por el ITESM. Cuenta con los estudios de Licenciatura en Derecho en la UNAM y de posgrado en la Universidad Carlos III de Madrid. Actualmente es asesora en la Coordinación de Institucionalización de la Perspectiva de Género del Tribunal Electoral del Poder Judicial de la Federación. 


\section{Introducción}

Juzgar con perspectiva de género significa realizar de manera efectiva la aplicación e interpretación de los derechos humanos, particularmente de las mujeres, en la impartición de justicia. Ello implica, a la larga, cambiar la perspectiva del derecho, concebida de forma tradicional como una institución patriarcal; crear un sistema de partidos que cuente con una representación política igualitaria; realizar, desde la perspectiva de género, un análisis de la legislación electoral y de los derechos políticos electorales; administrar las instituciones públicas bajo el prisma de la paridad.

Las acciones anteriores son asignaturas pendientes de la democracia mexicana toda vez que, a pesar de los avances, no han obtenido carta de naturalización absoluta en los sistemas político y jurídico mexicano. $Y$, sin embargo, si se nos permite recoger la frase de Galileo Galilei cuando era juzgado por la inquisición, "y sin embargo... se mueve". Este artículo pretende dar cuenta de ese movimiento por la igualdad en el Estado mexicano, así como de posibilidades de mejora en los sistemas de representación política y de partidos. El texto es descriptivo de qué se ha hecho, particularmente desde la función jurisdiccional en México, para garantizar el ejercicio de los derechos de las mujeres. Esperamos que sea de interés a las y los lectores.

\section{Los derechos de las mujeres}

El reconocimiento de los derechos humanos y por supuesto políticos y electorales de las mujeres no ha sido un proceso sencillo. Es resultado de transitar un doble camino. Por un lado, el impacto de las teorías feministas en el derecho al introducir en la dogmática sus conceptos, constituyó un importante parteaguas; por el otro, al conseguir a través de la movilización social, el reconocimiento de nuevos derechos en esta centuria y en las dos últimas.

En efecto, la búsqueda del reconocimiento de los derechos de las mujeres es una de las luchas sociales que nos han enseñado lo diferente que somos. En el siglo XIX y principios del XX, las feministas lucharon por conseguir la igualdad jurídica de hombres y mujeres, igualdad que concebían como la misma oportunidad para acceder a 
las instituciones que durante siglos les habían estado vedadas: las universidades y los cargos públicos. Esta igualdad jurídica se consiguió durante el siglo XX y se tradujo, entre otros aspectos, en condiciones de regulación especial sobre todo en el derecho social, principalmente en torno a los derechos laborales inherentes a la maternidad y tocaban otros ámbitos como las normas concernientes a la tutela de las hijas e hijos. La idea era garantizar una igualdad de oportunidades en contraposición del papel tradicional que las había ligado a la vida doméstica. El proceso de positivización no significó su cumplimiento en el plano fáctico.

Por otra parte, la positivización de los derechos laborales y civiles trajo aparejado también una serie de consecuencias paralelas. En muchos casos, las medidas laborales protectoras al embarazo se tradujeron en normas discriminatorias de las mujeres: muchas empresas privadas, pero también dependencias en el ámbito público, establecieron como requisitos de contratación de personal femenino el certificado de ingravidez de la aspirante. Esta práctica discriminatoria, entre otras, dio como resultado la dificultad de las mujeres de obtener y conservar sus empleos, ser segregadas para acceder a cargos directivos, y en general, la sobrerrepresentación del género femenino en los grupos salariales peor pagados. Otra dificultad a la que se enfrentaron las mujeres fue en el plano personal. Al formar parte actora en la sociedad, se generó un cambio en el esquema de la familia tradicional; el romper con el esquema de la masculinidad hegemónica generó nuevos tipos de familias (monoparentales, con una mujer a la cabeza), por lo que las mujeres tuvieron que enfrentar —en muchos casos- solas, los efectos negativos de la separación en el caso de hubiesen contado con una pareja, o bien, el ser señaladas por vivir esta situación. Lo anterior ha sido uno de los factores que contribuyen a la feminización de la pobreza, entendida como el proceso que en el último decenio ha ampliado la brecha que separa a los hombres de las mujeres atrapados en el ciclo de la pobreza.

Con la enumeración de las transformaciones antes señaladas, se puede observar la evolución del pensamiento feminista.

En la década de los noventa surgió un movimiento importante de defensa de los derechos humanos de las mujeres, en el que se defendían principalmente aquellos relativos a la violencia física ejercida en su contra, la mutilación genital, el tráfico de mujeres y el infanticidio selectivo de niñas. Este movimiento evidenció que la normatividad supranacional carecía de soluciones prácticas contra miembros no es- 
tatales de las naciones, en virtud de que permitían la permanencia de tradiciones culturales, familiares, económicas e inclusive religiosas, por encima de los mismos derechos humanos. Esto llevó al debate internacional, nuevamente, los derechos de las mujeres.

Ahora bien, lo importante es encontrar qué derechos. Nos parece que sería incorrecto establecer un catálogo toda vez que la discriminación a las mujeres puede darse en el ejercicio de cualquier derecho. Sin embargo, por las condiciones específicas, podrán argumentarse válidamente como derechos de las mujeres los siguientes:

1) El derecho a la inclusión de las mujeres en todos los sistemas sociales (tendiente a la abolición de todas las formas de discriminación a la mujer en la educación, empleo, representación política así como en la proscripción de la idea de que existen ámbitos masculinos y femeninos).

2) La libertad femenina (exteriorizada a través de cualquier derecho individual como la libertad de expresión, tránsito, asociación o reunión).

3) La inviolabilidad del cuerpo de la mujer (también podría ser entre hombres, pero se da con mayor frecuencia contra las mujeres) $y$, en general, el derecho a la protección gubernamental en contra de todas las formas de violencia física a la mujer.

4) La autodeterminación en el tema del aborto.

5) Los derechos inherentes al embarazo (no discriminación laboral a las mujeres por maternidad).

6) Los derechos a la decisión en torno a la reproducción (cuántas hijas e hijos y cuándo concebir).

7) Los derechos de representación política y administrativa en condiciones de paridad. A este último, nos referiremos a continuación.

\section{Juzgar con perspectiva de género: \\ la práctica de hacer visibles las discriminaciones al momento de impartir justicia}

Juzgar con perspectiva de género implica reconocer que el derecho es un texto susceptible de ser interpretado. En ese tenor, si el texto nor- 
mativo está escrito en un lenguaje masculinizado, misógino o francamente machista, lo procedente es hacer visibles tales discriminaciones y corregirlas en clave democrática. Pensamos, por ejemplo, en el Código Penal chiapaneco, que sanciona a la hija que ha sufrido el delito de incesto cometido por un hermano. ${ }^{1}$ Esta norma evidentemente está redactada en términos desfavorables hacia las mujeres, por lo que sería conveniente revisar su constitucionalidad frente a la aplicación cotidiana.

En ese tenor, la función judicial con perspectiva de género implica dar una lectura especializada del texto normativo, a fin de evitar cualquier tipo de discriminación expresa o implícita. En la materia electoral, el Tribunal Electoral del Poder Judicial de la Federación, principalmente a partir de la actual integración de la Sala Superior, pero también con algunos precedentes de la conformación anterior, ha desarrollado una actividad trascendente en materia de protección de los derechos político-electorales de las mujeres. A continuación damos cuenta de los precedentes más relevantes:

\section{Sustitución de candidatas afectando las cuotas de género}

En el expediente SUP-JRC-96/2008, el PVEM impugnó la sentencia dictada por el Tribunal Electoral del Distrito Federal, sosteniendo que la autoridad administrativa electoral y el órgano jurisdiccional local se habían excedido en sus atribuciones al imponer una sanción con base en una infracción calificada como grave, por sustituir a una candidata mujer por un hombre, afectando las cuotas de género de la legislación electoral, sin un fundamento adecuado. Para el partido actor, la decisión del Instituto Electoral del Distrito Federal de aprobar la sustitución de la candidata a jefa delegacional en Cuauhtémoc por un candidato hombre, se convertía en un incentivo para trasgredir las normas de cuota de género. La Sala Superior consideró que para la calificación de la conducta ilícita de no cumplir con la cuota de género en la lista de candidatos/candidatas a jefes delegaciones en el

1 Artículo 163. Se impondrá de tres a ocho años de prisión a los ascendientes que tengan relaciones sexuales con sus descendientes. La pena aplicable a estos últimos será de uno a cuatro años de prisión.

Se aplicará esta última sanción en caso de incesto entre hermanos. 
Distrito Federal en 2006, se debía atender al hecho de que la violación sancionada pudo haber sido evitada por la autoridad administrativa electoral. Por tanto, confirmó la imposición de la multa al PVEM y amonestó al Instituto Electoral del Distrito Federal para que, en ejercicio de sus funciones observara estrictamente la aplicación de las normas.

2. Constitucionalidad de distinciones por cuestión de género. La visión de la Sala Toluca

En el ST-JDC-295/2009, Gustavo Orozco Zepeda demandó la decisión de la presidencia del Comité Ejecutivo Nacional del PRI que determinó que debía registrarse a Blanca Villaseñor Gudiño como candidata a diputada federal por el 04 distrito electoral federal en Michoacán, con cabecera en Jiquilpan, por considerar que había sido tomada esa decisión "bajo el argumento de la equidad de género". El antecedente fue que, al celebrarse la Convención de delegados para elegir al o la candidata, existió un empate en las preferencias electorales. El CEN, ante esta circunstancia no prevista, determinó postular a la citada Blanca María Villaseñor Gudiño. Al inconformarse ante la Sala Regional Toluca, el actor combatía tal decisión. Sin embargo, la Sala Regional consideró que, cualquier distinción por cuestiones de género, para decidir qué candidato o candidata debe ser postulada en caso de empate, era acorde con la Constitución, si tenía como finalidad promover la equidad entre géneros, lo anterior, acorde con el derecho internacional de los derechos humanos.

Este criterio fue ratificado por la Sala Toluca en un asunto del Partido Acción Nacional respecto a la integración de la Delegación $\mathrm{Mu}$ nicipal de Cuautitlán Izcalli, Estado de México, en el expediente STJDC-86/2010.

\section{Alternancia en las listas de representación proporcional}

En el SUP-JDC-461/2009, Mary Telma Guajardo Villarreal impugnó la resolución emitida por la Comisión Nacional de Garantías del Partido de la Revolución Democrática relacionada con la aprobación de las candidaturas a diputados federales por el principio de representa- 
ción proporcional, específicamente respecto del lugar de la lista que le correspondió y por la que se declaró infundado el medio de defensa intrapartidario. La pretensión de la actora consistía en que se ordenara la modificación de la lista de candidatos a diputados federales, para que se le inscribiera en el tercer lugar de la lista, en vez de la cuarta posición. A su juicio, no se había cumplido con el requisito de regla de alternancia. La Sala Superior declaró fundado el motivo de diseño formulado por la actora. Por un lado, la Sala afirmó que la regla de alternancia para ordenar las candidaturas de representación proporcional consiste en colocar en forma sucesiva una mujer seguida de un hombre, o viceversa, hasta agotar las cinco candidaturas del segmento, de modo tal que el mismo género no se repita de manera consecutiva. La Sala considera que alternar implica el cambio, la variación o turno repetido, por lo que, el registro desarrollado por el partido político no logra la igualdad de oportunidades y paridad de género exigidas por las legislaciones aplicables porque se rompe el equilibrio entre ambos sexos y con ello, la nivelación de las posibilidades para ambos géneros de alcanzar un cargo de representación popular.

En ese tenor, la regla de alternancia permite a los partidos políticos cumplir con el deber de promover y garantizar la igualdad de oportunidades y procurar la paridad de género en la vida política del país, a través de postulaciones a cargos de elección popular puesto que incrementa la posibilidad de que los representantes electos a través de ese sistema electoral sean de ambos sexos.

\section{Cuotas de género en candidaturas propietarias y suplentes. La visión de la Sala Xalapa}

En el expediente SX-JRC-17/2010, el Partido de la Revolución Democrática y la coalición Mega Alianza Todos con Quintana Roo impugnaron la sentencia emitida por el Tribunal Electoral de Quintana Roo, en el juicio de inconformidad JIN/013/2010, el cual fue presentado en contra del registro de las planillas de candidatos postulados por el PRI para la elección de los ayuntamientos de Othón P. Blanco, Cozumel y Morelos, por la que se confirmó el registro de las referidas candidaturas, concluyendo para ello que la cuota de género para la postulación de candidaturas, había de aplicarse considerando de manera conjunta, tanto a candidaturas propietarias como a candidaturas suplentes. 
Respecto a la cuota de género, los actores se dolieron de que a su juicio, la responsable debió distinguir entre candidaturas propietarias y suplentes, sin partir del número total de candidaturas, para verificar el cumplimiento del porcentaje señalado por la cuota de género. La línea argumentativa fue la siguiente:

- El precepto constitucional local establecía la obligación de los partidos políticos de postular candidatos de ambos géneros, sin que uno sobrepase el $60 \%$ del total de las fórmulas que integran la planilla de candidatos a integrantes del ayuntamiento.

- Contrario a lo argumentado por la responsable en la sentencia impugnada, las candidaturas deben tomarse no por separado o aisladas, sino en fórmulas.

- La conclusión adoptada por la responsable no se apoyó en una interpretación armónica de la norma que prevé la cuota de género, con el resto de las normas que integran el sistema jurídico vigente en el estado de Quintana Roo, sino que aplicó el porcentaje sobre el total de candidaturas propietarias y suplentes consideradas individualmente.

- En ese tenor, no se conseguiría lograr de manera eficiente el objetivo de las cuotas de género, si se toma en cuenta la aplicación de la cuota de género sólo respecto a candidaturas propietarias, podría convertirse en un fraude a la ley, para que renunciaran para dejar a un suplente del género opuesto.

- El propósito de la cuota de género estriba en asegurar que las propuestas partidistas de ciudadanos para ocupar un cargo público guarden una proporción equilibrada entre géneros, con miras a conseguir una auténtica participación política de las mujeres, no sólo durante la contienda electoral o la época de campañas proselitistas, sino también, en caso de que resulten electas, que asuman el cargo.

- La cuota de género deberá entenderse como aplicable sobre fórmulas de candidatos, propietarias y suplentes, integradas por sujetos del mismo género.

\section{Alternancia y rotación en el Tribunal Electoral de Sonora}

En el SUP-JDC-28/2010, María Teresa González Saavedra impugna los acuerdos del 5 de febrero del año en curso, emitidos por el pleno 
del tribunal estatal electoral y de transparencia informativa del estado de Sonora, relativos a la designación de Luis Enrique Pérez Alviderez como presidente del citado tribunal.

La Sala Superior dio la razón a la actora porque en el artículo 22 de la Constitución Política del Estado de Sonora y en el numeral 312 del Código Electoral Estatal se advierte que la presidencia del tribunal debe elegirse por mayoría de votos de sus integrantes, pero además debe ser rotativa. Por lo que, al estar integrado el tribunal estatal por tres magistrados, y el presidente es electo por un periodo de tres años, debe observarse el principio de rotatividad, interpretado en el sentido de que rotativo significa alternancia, por lo que no existe reelección y la presidencia se debe alternar entre los magistrados del tribunales, aun cuando no necesariamente de la totalidad. Con ello, se privilegia el principio de paridad de género previsto en la Constitución.

\section{Conclusiones}

El sistema de impartición de justicia no ha logrado incorporar de forma transversal la perspectiva de género; aún no existe una vinculación real entre el derecho internacional, los tratados, y acuerdos internacionales, a los que México está obligado cumplir y el derecho interno. El lenguaje jurídico aún tiene tintes sexistas. Esto da como resultado una inequidad en el acceso a la justicia de las mujeres, pese a los esfuerzos de quienes todos los días buscan el reconocimiento pleno de los derechos humanos, políticos y electorales de éstas.

Los casos que se enumeraron dan cuenta de la posición institucional del Tribunal Electoral del Poder Judicial de la Federación al procurar realizar acciones que garanticen la igualdad en el acceso a la justicia. Falta mucho por hacer, eso es obvio, pero los avances están a la vista de todos.

Garantizar la alternancia en las listas de representación proporcional ha significado un primer golpe al fraude a la ley que representa la postulación de mujeres candidatas. Falta avanzar, al menos, en otros dos puntos: la obligación a nivel legal de que las mujeres candidatas propietarias tengan suplentes también mujeres, para evitar un nuevo caso de "Juanitas". Por otra parte, que los convenios de coalición reconozcan que en los casos de inelegibilidad de una fórmula de candida- 
tas mujeres, sea la siguiente fórmula de mujeres la que asuma el cargo, y no la siguiente de hombres.

Finalmente, respecto a la paridad, el debate apenas inicia. La resolución de Sonora es una primera aproximación a avanzar en el tema, pero la paridad implicará que el ejercicio del poder público sea distribuido de manera equitativa entre mujeres y hombres. Es preciso que se reconozca que cada espacio que ganen las mujeres será un espacio perdido por los hombres. Lo anterior es correcto, si vemos las cosas con una perspectiva histórica de subordinación y discriminación que es preciso que estas generaciones restituyan. 